\title{
Vitamin D levels in children with familial Mediterranean fever
}

\author{
Hatice Onur ${ }^{*}$, Hale Aral ${ }^{2}$, Vefik Arica ${ }^{3}$, Gamze Atalay Bercem ${ }^{1}$ and Ozgur Kasapcopur ${ }^{4}$
}

\begin{abstract}
Background: This study aimed to determine whether vitamin D deficiency is more common in children with familial Mediterranean fever (FMF) than in healthy individuals.

Methods: The study group consisted of 100 patients diagnosed with FMF and 50 healthy children. Serum baseline 25-hydroxyvitamin D levels and other related parameters were evaluated.

Results: The mean (standard deviation [SD]) vitamin D levels in patients with FMF and healthy controls were 24.78 (8.35) and $28.70(11.70) \mathrm{ng} / \mathrm{mL}$, respectively. Patients with FMF had significantly decreased vitamin D levels compared with those in healthy controls $(P=0.039)$. Vitamin $D$ levels were similar in patients with FMF with different MEFV mutations $(P=0.633)$. Age was significantly correlated with vitamin $\mathrm{D}$ levels $(r=-0.235, P=0.019)$. In addition, a negative correlation between parathyroid hormone and vitamin $D$ levels was detected $\left(r_{s}=-0.382, P<0.0001\right)$.

Conclusion: This study demonstrated that vitamin D levels are lower in children with FMF than in healthy controls. We speculate that vitamin D levels should be carefully examined, and nutritional supplementation may be required in patients with FMF. Further studies with larger patient populations are needed to confirm the frequency of vitamin D deficiency in patients with FMF.
\end{abstract}

Keywords: 25-hydroxyvitamin D, Familial Mediterranean fever, Children, Gene mutation

\section{Background}

Familial Mediterranean fever (FMF) is an autosomal recessive disease that is prevalent among eastern Mediterranean populations, mainly non-Ashkenazi Jews, Armenians, Turks, and Arabs [1]. Patients experience recurrent, self-limiting inflammatory febrile attacks, as well as abdominal, chest, and joint pain. The factors that trigger or terminate these periodic attacks are unknown. Some patients with FMF have chronic immune activation, reflected by subtle clinical signs of inflammation, such as chronic normocytic normochromic anemia, splenomegaly, decreased bone mineral density, persistent elevation of fibrinogen levels and erythrocyte sedimentation rates (ESRs), and growth retardation [2].

In recent years, the discovery of vitamin $\mathrm{D}$ receptors on immune cells and the fact that several of these cells produce vitamin $\mathrm{D}$ suggest that vitamin $\mathrm{D}$ may have immunoregulatory properties. Vitamin D, in addition to

\footnotetext{
* Correspondence: drhaticeakar@gmail.com

${ }^{1}$ Department of Pediatrics, Bursa Yuksek Ihtisas Training and Research Hospital, 152 Evler, Prof. Tezok street No: 2, Yıldırım/Bursa, Istanbul, Turkey Full list of author information is available at the end of the article
}

phosphorus and calcium, has pleiotropic immunomodulating effects [3]. Vitamin D status has been linked to the occurrence and severity of autoimmune and inflammatory diseases [4].

FMF is an inflammatory disease that is more common in populations surrounding Mediterranean sea. The disease is prevalent in $0.1 \%$ of the Turkish population, and one in five individuals is a carrier of mutations [1]. Our study is valuable, as it includes a large number of pediatric patients with FMF. As low-grade inflammation occurs in FMF, we aimed to determine whether vitamin D deficiency is more prevalent in children with FMF than in healthy individuals.

\begin{abstract}
Methods
Subjects

The study group included 100 patients with a diagnosis of FMF who received medical care at Istanbul Cerrahpasa Medical Faculty of Rheumatology outpatient clinics. Patients with other known chronic diseases were excluded. None of the patients was in the attack period of FMF. All patients were receiving treatment with colchicine, whereas
\end{abstract}


no patient in the control group was receiving any medication that could affect vitamin D levels. Blood samples were drawn in the summer (June-July 2013). The control group comprised 50 age-and sex-matched healthy children. Blood samples were taken from the healthy controls for another medical reason with parent approval. The diagnosis of FMF was established according to criteria defined by Yalcinkaya et al. [5]. The study was approved by the local ethics committee of the Istanbul Education and Research Hospital and was conducted in accordance with the Declaration of Helsinki.

\section{Measurements}

Blood samples were obtained from patients with FMF and controls. Serum samples for vitamin D measurements were obtained by centrifugation within $2 \mathrm{~h}$ after blood samples were drawn and frozen at $-80{ }^{\circ} \mathrm{C}$ prior to analysis. The frozen samples were transferred properly (on dry ice in the dark) to Acrbadem Labmed (Istanbul, Turkey). The experiments were performed using an Agilent 6460 triple quadrupole liquid chromatography (LC)/ mass spectrometry system equipped with an electrospray ionization ion source interface in the positive ion mode (Agilent Technologies, Santa Clara, CA, USA). The lower detection limit was $3.0 \mathrm{ng} / \mathrm{mL}$. At a mean of $16.13 \mathrm{ng} / \mathrm{mL}$, the inter-assay coefficient value $(\mathrm{CV})$ was $3.37 \%$, and at a mean of $50.96 \mathrm{ng} / \mathrm{mL}$, the inter-assay $\mathrm{CV}$ was $1.52 \%$ (Chromsystems Mass Check, Gräfelfing, Germany).

In the Istanbul Education and Research Hospital Central Biochemistry Laboratory, routine biochemical analyses of serum samples were performed using an Advia 2400 Chemistry System. Parathyroid hormone (PTH) levels were measured using a Centaur XP hormone analyzer, fibrinogen content was determined using a Sysmex CA1500 automated coagulometer, and $\mathrm{C}$-reactive protein (CRP) levels were measured using a BNII nephelometer (Siemens Healthcare Diagnostics Inc).

Gene mutations were detected previously and included in the retrospective file records of the patients with FMF. Plasma vitamin D levels were categorized as follows: sufficient, $25-80 \mathrm{ng} / \mathrm{mL}$; mild-moderate deficiency, $10-24 \mathrm{ng} / \mathrm{mL}$; and severe deficiency, $0-10 \mathrm{ng} / \mathrm{mL}$. These reference intervals for serum 25 . OH-D vit levels were reported by Acibadem Labmed (Istanbul, Turkey) compatible with the literature [6]. The reference intervals for vitamin $\mathrm{D}$ metabolites are method-dependent, and the lower limit of 25.OH-D vit levels considered sufficient for health is controversial, as vitamin D levels vary according to season, localization, skin type, nutritional status, sun exposure, and lifestyle [7].

\section{Statistical analyses}

Statistical analysis was performed using the Number Cruncher Statistical System 2004 (NCSS Systems, Kaysville,
UT, USA) and MedCalc (MedCalc Software, Broekstraat, Mariakerke, Belgium). Kolmogorov-Smirnov goodness-offit tests were used to determine whether the variables exhibited a Gaussian distribution. Normally distributed numerical variables were expressed as the mean (standard deviation $[\mathrm{SD}]$ ) if normally distributed, and values that lacked a normal distribution were expressed as the median (interquartile range $[\mathrm{IQR}])$. Pearson's chi-squared tests were used to compare categorical variables. Statistical comparisons of the two groups were performed using Student's $t$-tests for data with a Gaussian distribution or Mann-Whitney Utests for data with a non-Gaussian distribution. Pearson's correlation coefficient ( $r$ ), Spearman's rank correlation coefficient $\left(r_{s}\right)$, or a biserial correlation coefficient was used to evaluate the degree of association between two variables. Two-way analysis of variance was performed to identify a significant interaction effect between the independent variables. All statistical tests were two-sided, and $P<0.05$ denoted statistical significance.

\section{Results}

The demographic characteristics and main laboratory parameters of the patients and controls are summarized in Table 1. Among the patients with FMF, the median age at diagnosis of FMF was 6 years (IQR, $4-10$ years), and the

Table 1 Demographic characteristics and main laboratory parameters of patients with and without familial Mediterranean fever

\begin{tabular}{|c|c|c|c|}
\hline & $\begin{array}{l}\text { Familial Mediterranean } \\
\text { fever group (mean [SD]) } \\
(n=100)\end{array}$ & $\begin{array}{l}\text { Control group } \\
\text { (mean [SD]) } \\
(n=50)\end{array}$ & P-value \\
\hline $\begin{array}{l}\text { Age at investigation } \\
\text { (years) }\end{array}$ & $10.8(3.5)^{a}$ & $10.4(4.4)^{a}$ & 0.560 \\
\hline Female/male $(n)$ & $54 / 46$ & $25 / 25$ & 0.644 \\
\hline $\begin{array}{l}\text { Age at diagnosis } \\
\text { (years) }\end{array}$ & $6(4-10)^{b}$ & & \\
\hline $\begin{array}{l}\text { Duration of } \\
\text { colchicine use (years) }\end{array}$ & $3(2-5)^{b}$ & & \\
\hline Fibrinogen (mg/dL) & $288(63)^{b}$ & & \\
\hline $\operatorname{CRP}(\mathrm{mg} / \mathrm{dL})$ & $0.20(0.11-0.41)^{b}$ & & \\
\hline $\mathrm{ESR}(\mathrm{mm} / \mathrm{h})$ & $13(9-21)^{b}$ & & \\
\hline $\begin{array}{l}\text { Alkaline phosphatase } \\
(\mathrm{U} / \mathrm{L})\end{array}$ & $215(80)^{a}$ & & \\
\hline \multicolumn{4}{|c|}{ MEFV mutation test results $(n)$} \\
\hline M694V/M694V & 16 & & \\
\hline M694V/other & 34 & & \\
\hline Other/other & 37 & & \\
\hline Negative & 13 & & \\
\hline
\end{tabular}


median duration since onset was 3 years (IQR, 2-5 years). In total, 48 (48\%) patients had articular findings, and no patients had renal involvement. The presenting symptoms were abdominal pain and fever for 39 (39\%) patients, abdominal pain/fever/arthritis/arthralgia for 28 (28 \%) patients, isolated arthritis/arthralgia for 8 (8\%) patients, abdominal pain/fever/skin lesions for 5 (5\%) patients, fever/arthritis/arthralgia for 5 (5\%) patients, and other symptoms (chest pain, myalgia, and skin lesions) for 13 (13\%) patients. Additionally, 37 (37\%) patients had a family history of FMF.

Serum levels of calcium, phosphorus, PTH, and vitamin D were compared between the groups (Table 2). The mean (SD) vitamin D levels in patients with FMF and healthy controls were 24.78 (8.35) and 28.70 (11.70) $\mathrm{ng} / \mathrm{mL}$, respectively. Plasma vitamin D levels were significantly lower in patients with FMF than in the controls $(P=0.039)$

Vitamin D levels were deficient in $38.0 \%(19 / 50)$ and sufficient levels in $62.0 \%(31 / 50)$ of control group. In addition $57.0 \%(57 / 100)$ were deficient and $43.0 \%$ $(43 / 100)$ were in sufficient levels of FMF patients. $(P=$ 0.024) (Table 3). Pearson's chi-square test was used to compare observed levels with expected frequencies. The deficiency of the patients according to frequency of mild,moderate and severe deficiencies were $\% 2(2 / 100)$, $\% 31$ (31/100), \%26 (26/100) and for the control group $\% 6$ (3/50), \%14 (7/50),\%16 (8/50) respectively.

An increase in age was significantly correlated with a decrease in vitamin $\mathrm{D}$ levels $(r=-0.235, P=0.019)$. Additionally, a negative correlation was detected between PTH and vitamin D levels $\left(r_{s}=-0.382, P<0.0001\right)$. No significant correlation was noted between vitamin $D$ levels and the ESR or CRP levels.

Plasma vitamin D levels were not significantly different between patients with $(n=48)$ and without articular symptoms $(n=52)(23.72 \quad[7.93] \mathrm{ng} / \mathrm{mL}$ versus 25.20 [8.99] $\mathrm{ng} / \mathrm{mL}, P=0.328)$.

Meanwhile, plasma vitamin $D$ levels were similar among patients with FMF with different $M E F V$ mutations $(P>0.05)$ (Table 4$)$. The most prevalent mutations detected as M694V HT $(N=18, \% 18)$ and M694 $H M(N=16, \% 16)$ respectively.
Table 3 Vitamin D levels according to cut off levels

\begin{tabular}{llll}
\hline & $\begin{array}{l}\text { Familial Mediterranean } \\
\text { fever group } \\
(n=100)\end{array}$ & $\begin{array}{l}\text { Control group } \\
(n=50)\end{array}$ & $P$-value \\
\hline $\begin{array}{l}\text { Vitamin D } \\
<25 \mathrm{ng} / \mathrm{mL}(\mathrm{n}, \%)\end{array}$ & $57(57.0 \%)$ & $19(38.0 \%)$ & 0.024 \\
$\begin{array}{l}\text { Vitamin D }= \\
25-80 \mathrm{ng} / \mathrm{mL}(\mathrm{n}, \%)\end{array}$ & $43(43.0 \%)$ & $31(62.0 \%)$ & \\
\hline
\end{tabular}

\section{Discussion}

Our study established that vitamin D deficiency is present in a large number of Turkish children diagnosed with FMF.

The influence of vitamin D deficiency on inflammation is being explored, but studies have not demonstrated a causative effect. FMF is autoinflammatory disease in which $M E F V$ mutations change pyrin protein and thus inflammasome activity in cells of innate immune system [2]. The vitamin D effect on innate immun cells also investigated in other autoinflamatuar diseases like Behcet Disease(B.D.).Do JE et al. underlined the immunomodulatrory effect of vitamin $\mathrm{D}$ through down regulation of Toll-like receptor(TLR) expression in human monocytes. They also suggested that vitamin D may have an immunomodulatory effect on innate immunity-mediated inflammation in BD [8].

Some researchers hypothesized that low vitamin D is the consequence of a chronic inflammatory process caused by persistent infection [9]. The mechanism by which vitamin $\mathrm{D}$ reduces inflammation remains poorly understood. $\mathrm{T}$ helper cells playing a crucial role in FMF pathogenesis produce interferon (IFN)-gamma and tumor necrosis factor (TNF)-beta [10, 11]. Aypar et al. identified elevated IFN-gamma levels produced by Th- 1 cells during FMF attacks compared to those in healthy controls and suggested that Th-1 polarization may trigger inflammation in patients with FMF [12]. Vitamin D, which possesses immunomodulatory effects, inhibits the production of interleukin (IL)- 6 and IFN-gamma by reducing the differentiation and maturation of myeloid, Th- 1 , and Th17 cells $[13,14]$. Koklu et al. also reported elevated IFN gamma levels in patients with FMF during both attack and attack-free periods [15]. Additionally, some researchers

Table 2 Serum calcium, phosphorus, PTH, and plasma vitamin D levels in patients with and without familial Mediterranean fever

\begin{tabular}{llll}
\hline & $\begin{array}{l}\text { Familial Mediterranean fever group } \\
(n=100)\end{array}$ & $\begin{array}{l}\text { Control group } \\
(n=50)\end{array}$ & $P$-value \\
\hline Calcium (mg/dl) (mean [SD]) & $9.6(0.5)$ & $9.8(0.4)$ & $<0.01$ \\
Phosphorus (mg/dl) (median [IQR]) & $4.9(4.5-5.2)$ & $4.8(4.4-5.1)$ & 0.318 \\
PTH (pg/mL) (median [IQR]) & $49.9(28.7-64.8)$ & $34.2(24.2-53.2)$ & 0.024 \\
$25-\mathrm{OH}$ vitamin D (ng/mL) (mean [SD]) & $24.78(8.35)$ & $28.70(11.70)$ & 0.039 \\
\hline
\end{tabular}

PTH parathyroid hormone, SD standard deviation, IQR interquartile range 
Table 4 Vitamin D levels in patients with familial Mediterranean fever and different MEFV mutations

\begin{tabular}{lllll}
\hline & $\begin{array}{l}\text { M694V/M694V } \\
(n=16)\end{array}$ & $\begin{array}{l}\text { M694V/Other } \\
(n=34)\end{array}$ & $\begin{array}{l}\text { Other/Other } \\
(n=37)\end{array}$ & $\begin{array}{l}\text { Negative } \\
(n=13)\end{array}$ \\
\hline Vitamin D (ng/mL) (mean [SD]) & $23.71(9.94)$ & $26.35(9.84)$ & $23.85(5.52)$ & $24.64(9.07)$ \\
\hline
\end{tabular}

$S D$ standard deviation

connected low vitamin D levels to malabsorption of the vitamin as a result of colchicine treatment. Padeh et al. reported that $14 \%$ of patients developed diarrhea during colchicine treatment [16].

We detected significantly lower serum 25-hydroxy vitamin $D$ levels among patients with FMF than in matched controls $(P<0.01)$, and female patients with FMF were most strongly affected. Female $(N=54)$ and male $(N=46)$ patient's mean vitamin $\mathrm{D}$ levels were 23.09 (18.79-26.53) and $26.01(20.79-32.35)$ respectively $(P=0.014)$. Most previous studies were conducted in adults with FMF. Recently, Erten et al. [17] and Kisacik et al. [18] detected significantly lower serum 25-hydroxyvitamin D levels among patients with FMF than in matched controls $(P<0.001)$. Female patients with FMF were also most greatly affected in the study by Erten et al. [17]. They associated this result with styles of dress, low activity levels, and inadequate exposure to sunlight.

Chronic inflammation is associated with a decrease in bone mineral density in patients with various inflammatory diseases, and attack-free patients with FMF have considerably lower T-scores at the femur neck and lumbar spine than healthy individuals, reflecting their increased risk of developing early-onset osteoporosis [19-21]. Inflammatory activity in patients with FMF plays a major role in the pathophysiology of bone loss. This may be mediated by substances regulating both the inflammatory process and bone turnover [22]. Alterations in vitamin D metabolism can cause increases in bone resorption [23]. Osteoporosis in patients with FMF can also be related to decreased vitamin D levels [17]. Similarly, we detected a negative correlation between vitamin D and PTH levels, and a negative correlation between alkaline phosphatase and vitamin D levels has been reported, emphasizing the effects of vitamin D deficiency in patients with FMF. We propose that convenient nutritional supplementation would prevent the likely development of osteoporosis in patients with FMF. In a recent study, Zhang et al. supported the idea that serum vitamin $\mathrm{D}$ levels should be maintained at more than $30 \mathrm{ng} / \mathrm{mL}$ in the physiologic range to achieve sufficient anti-inflammatory effects [24]. Erten et al. concluded that vitamin D levels were significantly lower in adult patients who presented with joint symptoms as the first presentation than in those who presented with abdominal attacks. In our study, plasma vitamin D levels were not significantly different between patients with and without articular symptoms [17]. We speculate that this finding may be associated with the ages of patients in our study.
Some authors also detected increased inflammation in carriers of $M E F V$ mutations [25]. We investigated this association, but no significant correlation was detected $(P=0.633)$. Erten et al. [17] demonstrated that increased levels of inflammatory markers (ESR and fibrinogen) in patients with FMF were correlated with lower vitamin D levels. We also investigated this association but found no significant correlations among these markers $(P>0.05)$. This indicates that colchicine treatment suppressed inflammation. Increased inflammation exists in the attack period, and thus, we are planning to investigate vitamin D levels in this period in our future studies.

In a recent study, Anık et al. [26] also detected decreased vitamin D levels in children and indicated that the cumulative colchicine dose appears to negatively affect vitamin D levels. It was concluded that colchicine inhibited the functions of intracellular microtubules, which are essential components of the normal genomic response to vitamin D. Defects in the microtubular network attributable to colchicine use may reduce vitamin D levels because of increased production of $1,25(\mathrm{OH})$ vitamin D and 24,25(OH) vitamin D [26, 27]. Future studies should investigate the potential association between the colchicine dose and vitamin D status.

Our study had some limitations. We could not consider variables that can influence vitamin $\mathrm{D}$ levels such as dietary intake, physical activity status, sunlight exposure, increased skin pigmentation, and genetic polymorphisms of vitamin $\mathrm{D}$ receptors. In addition, the associations among the cumulative colchicine dose, acute attack periods, and severity scores have not been examined thoroughly. Our planned studies will investigate these associations.

To date, few studies have investigated vitamin D deficiency in patients with FMF. As our study is the first to include a large number of patients with FMF and controls, it has significant validity.

\section{Conclusion}

In conclusion, scientific research has not clarified whether vitamin D deficiency is a consequence or cause of inflammatory disease. This study demonstrated that vitamin D levels are lower in children with FMF than in healthy controls. We speculate that vitamin D levels should be carefully examined, and nutritional supplementation may be required in patients with FMF. Further studies with larger patient populations are needed to investigate vitamin $\mathrm{D}$ deficiency in patients with FMF. 


\section{Abbreviations}

CRP: C-reactive protein; ESR: erythrocyte sedimentation rate; FMF: familial Mediterranean fever; IFN: interferon; MEFV: mediterranean fever; PTH: parathyroid hormone; SD: standard deviation; Th-1: T helper-1; TLR: toll-like receptor; TNF: tumor necrosis factor.

\section{Competing interests}

The authors declare that they have no competing interests. The manuscript has been read and approved by all authors. It is not under active consideration for publication, it has not been accepted for publication, nor has it been published previously.

\section{Authors' contributions}

$\mathrm{CLH}$ and DRH contributed equally to the drafting of the manuscript. All authors have read and approved the final manuscript.

\section{Author details}

'Department of Pediatrics, Bursa Yuksek Ihtisas Training and Research Hospital, 152 Evler, Prof. Tezok street No: 2, Yıldırım/Bursa, Istanbul, Turkey. ${ }^{2}$ Department of Biochemistry, Istanbul Training and Research Hospital, Istanbul, Turkey. ${ }^{3}$ Department of Pediatrics, Yeniyuzyıl University, Gaziosmanpasa Hospital, Istanbul, Turkey. ${ }^{4}$ Department of Pediatrics Rheumatology, Cerrahpasa Medical Faculty, Istanbul University, Istanbul, Turkey.

\section{Received: 21 March 2016 Accepted: 25 April 2016}

\section{Published online: 27 April 2016}

\section{References}

1. Tunca M, Akar S, Onen F, Ozdogan H, Kasapcopur O, Yalcınkaya F, et al. Familial Mediterranean fever (FMF) in Turkey: results of a nationwide multicenter study. Medicine (Baltimore). 2005;84:1-11.

2. Ben-Zvi I, Livneh A. Chronic inflammation in FMF: markers, risk factors, outcomes and therapy. Nat Rev Rheumatol. 2011;7:105-12.

3. Cutolo M. Vitamin D, or hormone D deficiency in autoimmune rheumatic diseases, including undifferentiated connective tissue disease. Arthritis Res Ther. 2008;10:123.

4. Moghaddami M, Mayrhofer G, Anderson PH, Morris HA, Van Der Hoek M, Cleland LG. Efficacy and mechanisms of action of vitamin D in experimental polyarthritis. Immunol Cell Biol. 2012;90:168-77.

5. Yalçinkaya F, Ozen S, Ozçakar ZB, et al. A new set criteria for the diagnosis of familial Mediterranean fever in childhood. Rheumatology (Oxford). 2009; 48:395-8.

6. Alan HBW. Tietz Clinical Guide to Laboratory Tests. 4th ed. Missouri: WB Saunders Company; 2006. p. 1138.

7. Rsteli J, Winter WE, Kleerekoper M, Risteli L. Disorders of bone and mineral metabolism. In: Burtis CA, editor. Tietz Fundamentalis of Clinical Chemistry and Molecular Diagnostics. 7th ed. Bruns: Saunders; 2015. p. 741-68.

8. Do JE, Kwon SY, Park S, Lee ES. Effects of vitamin D on expression of Toll-like receptors of monocytes from patients with Behcet's disease. Rheumatology (Oxford). 2008;47(6):840-8.

9. Mangin M, Sinha R, Fincher K. Inflammation and vitamin D: the infection connection. Inflamm Res. 2014;63(10):803-19.

10. Podolsky DK. Inflammatory bowel disease (2). New Engl J Med. 1991;325: 1008-16.

11. Peterlik M, Cross HS. Dysfunction of the vitamin D endocrine system as common cause for multiple malignant and otherchronic diseases. Anticancer Res. 2006;26:2581-8.

12. Aypar E, Ozen S, Okur H, Kutluk T, Besbas N, Bakkaloglu A. Th1 polarization in familial Mediterranean fever. J Rheumatol. 2003;30(9):2011-3.

13. Daniel C, Sartory NA, Zahn N, Radeke HH, Stein JM. Immune modulatory treatment of trinitrobenzene sulfonic acid colitis with calcitriol is associated with a change of a T helper (Th) 1/Th17 to a Th2 and regulatory $T$ cell profile. J Pharmacol Exp Ther. 2008;324:23-33.

14. Lira FS, Rosa JC, Cunha CA, Ribeiro EB, do Nascimento CO, Oyama LM, et al. Supplementing alpha-tocopherol (vitamin E) and vitamin D3 in high fat diet decrease IL-6 production inmurine epididymal adipose tissue and 3T3-L1 adipocytes following LPS stimulation. Lipids Health Dis. 2011;10:37.

15. Koklu S, Ozturk MA, Balci M, Yuksel O, Ertenli I, Kiraz S. Interferon-gamma levels in familial Mediterranean fever. Joint Bone Spine. 2005;72:38-40.
16. Padeh $S$, Gerstein M, Berkun Y. Colchicine is a safe drug in children with familial Mediterranean fever. J Pediatr. 2012;161:1142-6.

17. Erten S, Altunoglu A, Ceylan GG, Maras Y, Koca C, Yuksel A. Low plasma vitamin D levels in patients with familial Mediterranean fever. Rheumatol Int. 2012;32:3845-9. 15.

18. Kisacik B, Kaya Z, Pehlivan Y, Tasliyurt T, Sayarlioglu M, Onat AM. Decreased vitamin D levels in patients with familial Mediterranean fever. Rheumatol Int. 2013;33:1355-7.

19. Yuksel S, Samli H, Colbay M, et al. Increased serum osteoprotegerin levels associated with decreased bone mineral density in familial Mediterranean fever. Tohoku J Exp Med. 2009:217:321-7.

20. Suyani E, Ozturk MA, Deger SM, Demirag MD, Goker B, Haznedaroglu S. Decreased bone mineral density in adult familial Mediterranean fever patients: a pilot study. Clin Rheumatol. 2008;27:1171-5.

21. Yildırım K, Karatay S, Cetinkaya R, et al. Bone mineral density in patients with familial Mediterranean fever. Rheumatol Int. 2010;30:305-8.

22. Lange U, Teichmann J, Strunk J, Müller-Ladner U, Schmidt KL. Association of 1.25 vitamin D3 deficiency, disease activity and low bone mass in ankylosing spondylitis. Osteoporos Int. 2005;16:1999-2004.

23. Warner AE, Arnspiger SA. Diffuse musculoskeletal pain is not associated with low vitamin D levels or improved by treatment with vitamin D. J Clin Rheumatol. 2008:14:12-6.

24. Zhang Y, Leung DY, Richers BN, Liu Y, Remigio LK, Riches DW, Goleva E. Vitamin D Inhibits Monocyte/macrophage Pro-inflammatory Cytokine Production by Targeting Mitogen-Activated Protein Kinase Phosphatase-1. J Immunol. 2012;188(5):2127-35.

25. Ozen S. Mutations/polymorphisms in a monogenetic autoinflammatory disease may be susceptibility markers for certain rheumatic diseases: lessons from the bedside for the benchside. Clin Exp Rheumatol. 2009;27(2 Suppl 53): S29-31.

26. Anık A, Catı G, Makay B. Decreased vitamin D levels in children with familial Mediterranean fever. Int J Rheum Dis. 2014;17:321-6.

27. Kamimura S, Gallieni M, Zhong M, Beron W, Slatopolsky E, Dusso A Microtubules mediate cellular 25-hydroxyvitamin D3 trafficking and the genomic response to 1,25-dihydroxyyvitamin D3 in normal human monocytes. J Biol Chem. 1995;270:22160-6.

\section{Submit your next manuscript to BioMed Central and we will help you at every step:}

- We accept pre-submission inquiries

- Our selector tool helps you to find the most relevant journal

- We provide round the clock customer support

- Convenient online submission

- Thorough peer review

- Inclusion in PubMed and all major indexing services

- Maximum visibility for your research

Submit your manuscript at www.biomedcentral.com/submit
) Biomed Central 